\title{
AÇÃO CIVIL PÚBLICA: LEGIMITIDADE AD CAUSAM DE SINDICATO PARA INGRESSO NO POLO ATIVO
}

\author{
Adair Batista Nepomuceno, Rachel Lopes Queiroz Chacur \\ Universidade do Oeste Paulista, UNOESTE, Curso de Direito. Presidente Prudente, SP. E-mail: \\ adairbn@bol.com.br, rachel@unoeste.br.
}

\section{RESUMO}

O presente trabalho objetiva avaliar os motivos que restringem a atividade proficiente de sindicatos no polo ativo de eventual ingresso de ação civil pública. A questão que se tentará esclarecer traz direto nexo de conexão com a presença de determinado órgão público que constitucionalmente possui como atribuição fiscalizar o ente público, contudo, pelos meandros do novel política, seus líderes se embrenharam na própria atividade política e que deveriam investigar, contudo, por compadrio, atuam com leniência, tolerância e até descaso. É interessante constar que, na contra face da moeda, o fiscalizado do fiscalizador constitucional é, hoje, o grande mote de sua atuação institucional. Assim formulado o debate, apresenta-se a proposta com a definição por vários doutrinados de conceitos jurídicos pertinentes, tais como, o que é ação, as condições da ação e a legitimidade extraordinária.

Palavras-Chave: sindicato - legitimidade ad causam - improbidade administrativa - ação civil pública ações civis coletivas.

\section{ABSTRACT}

This study aims to evaluate the reasons that restrict proficient activity of unions in active polo eventual entry of civil action. The question that will try to clarify brings direct connection connection with the presence of particular public body that constitutionally has the attribution to supervise the public entity, however, the intricacies of the novel politics, its leaders penetrated in their own political activity and should investigate, but by cronyism, act with leniency, tolerance and even neglect. It is interesting to state that, in the face against the currency, supervised the constitutional watchdog today is the great theme of its institutional performance. Thus formulated the debate presents the proposal to the definition of several indoctrinated relevant legal concepts such as, what is action, action conditions and the extraordinary legitimacy.

Key words: union - d legitimacy cause - improper conduct - civil action - collective civil actions. 


\section{INTRODUÇÃO}

É fato notório que a propositura de uma ação civil pública encontra-se delimitado pelos legitimados ativos, definidos pelo artigo 5ㅇ da Lei 7347/85, contudo é nos bancos acadêmicos que se devem iniciar as discussões de temas controversos e controvertidos. A semente deve ser, ao menos, jogado no solo para que haja expectativa de que uma bela árvore nasça e cresça, porém os frutos só surgiram se bem alimentadas suas raízes. Assim se pode justificar o tema que se propõe a debater.

O objetivo geral é discutir a possibilidade de estender a atuação dos sindicatos no polo ativo de eventual ação civil pública, frente à restrição legal e doutrinária apresentadas pela Lei n. 7347/85 (Lei da Ação Civil Pública). Os objetivos específicos são: a) Aprofundar o debate sobre a legitimidade ad causam de sindicatos no ingresso de ação de improbidade administrativa, limitada, hoje, nas ações coletivas de interesses exclusiva de seus filiados; b) Demonstrar cabalmente que qualquer sindicato tem interesse e legitimidade em ingressar com ações de improbidade para defender judicialmente direitos difusos e coletivos da sociedade, em especial, em matéria que traga reflexos direta e indiretamente a seus filiados; c) Discutir posições doutrinárias acerca da capacidade ad causam das associações para o ingresso de ações civis e coletivas; d) Discorrer sobre o receio do Ministério Público em aceitar que sindicatos, associações e defensoria pública figure como titular de ações civis públicas, e; e) Identificar se há discussão no Congresso Nacional projeto de lei que venha a incluir além dos sindicatos outras entidades entre os, hoje, legitimados pela lei de improbidade administrativa, previstas no artigo 17 da Lei 8429/1992.

A discussão sobre a possibilidade de que o Sindicato seja parte legítima e ativa no ingresso de uma ação de improbidade administrativa aflorou a partir da constatação de que determinados fatos administrativos vêm sendo corriqueiramente praticados nas entranhas do próprio ente gestor, sem que haja a coerção que se espera por parte daquele que constitucionalmente detém como prerrogativa sua inibição. O sindicato, por estar próximo de seus filiados, possui a sensibilidade e peculiares comprovações da prática dos desmandos realizados pelo gestor público e que nenhum outro órgão poderia obter. A prática de infrações, por exemplo, perpetuada pela direção do Ministério Público e de Tribunal de Justiça de Estado deve ser denunciado a quem? Aos respectivos Conselhos Nacionais? Não vejo lógica nessa atitude, pois esses grupos são extremamente corporativistas e, no fim, criam empecilhos para dificultar o acesso e ter sua pretensão analisada. Essa junção de fatores garante compromisso e fidelidade ao sindicato para a propositura direta do pleito judicial, uma vez que há nítido interesse subjacente em solucionar a questão de ordem prática e corriqueira que, repisa-se, ocorre seio de inúmeros órgãos públicos nacionais.

Estudando-se as Leis que normatizam todo o arcabouço das ações cíveis, as doutrinas e doutrinadores conceituados, a leitura da jurisprudência poder-se-á alcançar o atalho desejado para que se efetive a pretensão de autorizar o sindicato a ingressar, na condição de titular, uma ação civil pública que inibe e obrigue o gestor público a repensar sua iniciativa administrativa quando a frente de determinado órgão público.

\section{REVISÃO DE LITERATURA}

O operador do direito para debater determinados temas jurídicos deve aprofundar em seus conhecimentos. Não seria diferente para valer a discussão sobre o tema ora apresentado. O caminho, portanto, inicia-se com a apresentação de como são conceituado tópicos de grande relevância pelos mais conceituados professores, doutrinadores e juízes de nossos tribunais.

Assim, ensina o professor (NEVES, 2009, 72) que, com o desenvolvimento da ciência processual, surgiram inúmeras teorias a respeito da natureza jurídica da ação, contudo algumas 
delas apenas nutrem interesse histórico, já outras com profundo interesse atual. Em sua cátedra esclarece que:

A Teoria Imanentista considera o direito de ação como o próprio direito material em movimento, porquanto se entendia que era a reação de uma agressão ou de uma ameaça. Para os defensores dessa teoria, o direito de ação é um poder que o indivíduo possui contra o seu adversário e não contra o Estado, sendo o processo um mero procedimento, ou seja, um conjunto de atos coordenados visando à obtenção de um objetivo final.

A Teoria Concreta da Ação distinguiu a o direito de ação do direito material. Segundo seus defensores, a ação é um direito do indivíduo contra o Estado, com a finalidade de obter uma sentença favorável e, ao mesmo passo, um direito contra o adversário. A Teoria Abstrata do Direito de Ação manteve o entendimento de que o direito de ação e o direito material não se confundem e, indo além, ao se posicionar no sentido de que o direito de ação é independente do direito material. Esclarece que o direito de ação, portanto, é o direito abstrato de obter um pronunciamento do Estado, por meio de uma decisão judicial. E conclui que 'para os defensores dessa teoria, o direito de ação é abstrato, amplo, genérico e incondicionado, não existindo nenhum requisito que precise ser preenchido para sua existência. A Teoria Eclética o direito de ação não se confunde com o direito material, a qual existe de forma autônoma e independente, contudo não será incondicionada e genérica, pois tal ação só existirá quando o autor tiver o direito a um julgamento de mérito, tanto faz favorável ou desfavorável. A ação está estritamente condicionada à presença das condições da ação, qual seja, a legitimidade das partes, o interesse processual e possibilidade jurídica do pedido. As condições da ação não se confundem com o mérito, as quais devem ser analisadas preliminarmente e, em caso de ausência de um desses elementos, gerará uma sentença terminativa de carência de ação (art. 267, VI, do CPC). Há de ressaltar que o C.P.C./1973 adotou a Teoria Eclética, do mestre italiano ENRICO TULLIO LIEBMAN, como base para a Teoria da Ação, sendo que, inclusive, figura disposta no artigo 3 caput daquela lex, de tal forma que para a propositura de uma ação obrigatoriamente há de observar o interesse e legitimidade, sem os quais o órgão judiciário extinguirá o processo sem resolução do mérito (inc. IV, do art. 267 do CPC/1973). A recente Teoria da Asserção identificada entre a teoria a abstrata e a eclética. Por essa teoria, as condições da ação devem ser analisadas pelo Juiz em face dos elementos fornecidos pelo autor em sua exordial, sem nenhum desenvolvimento cognitivo. Os defensores dessa teoria entendem que o Juiz, embasado no princípio da economia processual, deverá extinguir a ação sem julgamento do mérito, ao constatar sumariamente, a ausência de uma ou mais condições da ação.

No campo das "CONDIÇÕES DA AÇÃO", segundo a Teoria Eclética, a que foi adotada pelo legislador brasileiro e com marcas profundas no CPC/1973, o exercício do direito de ação estaria condicionada à presença de três elementos: a legitimidade das partes, o interesse processual e possibilidade jurídica do pedido, sendo que a ausência de um desses elementos conduziria a ação à extinção sem resolução do mérito. Esclarece a doutrina majoritária (FLEXA, 2015, 54), que, na vigência do CPC/1973, as condições da ação enfrentaram duras críticas da doutrina por não integrarem o juízo de admissibilidade do processo, mas o próprio mérito. Dessa forma, como as condições da ação não figuravam como juízo de admissibilidade, sua ausência não poderia gerar uma sentença sem resolução de mérito, como previsto no art. 267, VI, CPC/1973. Assim, a sentença que viesse a reconheceu sua ausência deveria julgar improcedente o pedido. FREDIE DIDIER JR. atualiza esse conceito e ensina que o atual CPC não mais se vale da categoria "condição da ação" como gênero, de que são espécies a legitimidade ad causam e o interesse de agir, contudo continua a regular essas espécies de requisito de admissibilidade (2016, p. 344). 
A Constituição Federal, em seu inciso XXXV do artigo 5ạ, garante que todos podem acionar a atividade judiciária. Entretanto essa garantia não é absoluta, pois ninguém está autorizado a levar a juízo, de modo eficaz, toda e qualquer demanda. Assim, deve existir um vínculo entre os sujeitos da demanda e a situação jurídica afirmada que lhe autorize a gerir o processo em que ocorrerá a discussão (DIDIER JR, 2016, p. 345). Falou-se, aqui, sobre a legitimidade das partes. Essa é base para se cravar a noção de legitimidade ad causam.

DIDIE JR. assevera que a legitimidade para agir (ad causam petendi ou ad causam agendum) é requisito de admissibilidade que se precisa investigar no elemento subjetivo da demanda: os sujeitos. E sacramenta:

Não basta que se preencham os pressupostos processuais subjetivos para que a parte possa atuar regularmente em juízo. É necessário, ainda, que os sujeitos da demanda estejam em determinada situação jurídica que lhes autorize a produzir o processo em que se discuta aquela relação jurídica de direito material de deduzida em juízo. (DIDIER JR., 2016, p. 345)

Conceitua a legitimação ordinária e legitimação extraordinária. Expõe que há a primeira quando se atribui a um ente o poder de conduzir validamente um processo em que se discute uma situação jurídica de que afirma titular. Há legitimação extraordinária quando se atribui a um ente o poder de conduzir validamente um processo em que se discute situação jurídica cuja titularidade afirmada é de outro sujeito. E sacramenta, ao desnuviar que:

na legitimação ordinária, age-se em, nome próprio da defesa dos próprios interesses; na legitimação extraordinária, age-se em nome próprio da defesa de interesse alheio (DIDIER, 2016, 176 verso)

A lei brasileira preferiu, diferentemente do que se constata em outros países, indicar o rol dos legitimados e estabeleceu parâmetros objetivos, como exemplos, a representação no Congresso Nacional, para os partidos políticos e a existência legal (legalmente constituída para as associações) e pré-constituição (em funcionamento há pelo menos um ano), para as associações, no mandado de segurança coletivo, ou a legitimação da administração direta e indireta, Ministério Público, Defensoria Pública e associações no caso da Lei n. 7347/1985. Assim, as três técnicas de legitimação mais utilizada em ações coletivas e que foram adotadas no Brasil: a) legitimação do particular (qualquer cidadão, por exemplo, na ação popular, Lei 4717/1965); b) legitimação de pessoas jurídicas de direito privado (sindicatos, associações, partidos políticos, por exemplo, mandado de segurança coletivo, art. 5ํ, LXX, da CF/1988); ou; c) legitimação de órgãos do Poder Público (Ministério Público e Defensoria Pública, por exemplo, na ação civil pública, prevista na lei n. 7347/1985) (DIDIER Jr., 2016, p. 182 e verso).

No Interesse Processual, a ideia de interesse de agir, também chamado de interesse processual, está intimamente associada à utilidade da prestação jurisdicional que se pretende obter com a movimentação da máquina jurisdicional (NEVES, 2009, p.78-verso). Por óbvio, o demandante deve demonstrar que possui uma questão pendente a ser tratada e precisa receber o provimento judicial para acalentar sua expectativa. Assim, o interesse no litígio deve se assentar nessa premissa. Nessa acepção, ensina que a petição inicial deve conter a exposição dos fatos e dos fundamentos jurídicos do pedido, os quais formam a denominada causa de pedir (art. 393, III, do CPC). Esclarece que a causa de pedir é o fato ou conjunto de fatos jurídicos (fato(s) da vida juridicizado(s) pela incidência da hipótese normativa) e a relação jurídica, efeito daquele fato jurídico, trazidos pelo demandante como fundamento de seu pedido (DIDIER JR., 2016, p. 560 e verso).

O terceiro requisito, qual seja, a possibilidade jurídica do pedido, tem-se que toda petição inicial deve conter um pedido, cuja ausência canalizará a ação ao indeferimento, uma vez que exordial sem pedido é inepta. Dispunha o artigo 286, do CPC/1973, que o pedido deveria ser certo ou 
determinado. Numa análise abstrata e realizada a priori, o juiz deve considerar hipoteticamente que o autor tem a razão em tudo que alega, e a partir daí verificar se existe a vedação legal ao que pretende receber, o que impedirá a continuidade do processo em razão de sua manifesta inutilidade (NEVES, 2009, p. 77).

Os elementos da ação se prestam a identificar a ação, porquanto de grande importância quando se quer comparar uma ação com outra que esteja tramitando. É notório afirmar que duas ações são iguais, similares ou totalmente diferentes sem que se faça a comparação entre esses itens presente em todas as ações. Daí a importância de discorrer brevemente sobre tal tema. São três os elementos de uma ação: partes, pedido e causa de pedir.

[...] para Chiovenda, parte é o sujeito que pede ou contra quem se pede tutela jurisdicional. Já, para Liebman, cujo entendimento era mais amplo, parte é todo o sujeito que participa da relação jurídica processual em contraditório defendendo interesse próprio ou alheio (NEVES, 2009, p-83).

A grande maioria doutrina nacional entende que ambos os conceitos podem conviver em harmonia, uma vez que, conforme a pretensão arguida, uma dessas teses podem se amoldar à cada situação fática. Sob a ótica processual, preconiza o pedido como sendo a providência jurisdicional pretendida, qual seja, a obtenção da condenação, da constituição, da mera declaração. E, sob a ótica material, representa o bem da vida perseguido, ou seja, o resultado prático que o demandado pretende obter com a demanda judicial.

\section{CONCLUSÃO}

A doutrina pátria majoritária adotou a Teoria da Substanciação, a qual entende que a causa de pedir, independente da natureza da ação, é formada apenas pelos fatos jurídicos narrados pelo autor. Considera-se a natureza jurídica da AÇÃO CIVIL PÚBLICA como sendo uma ação cível e de caráter público, por meio da qual se protege o Meio Ambiente os consumidores e os direitos difusos e coletivos, entre outros. A Lei n. 7347/1985 é que disciplina a ação civil pública de responsabilidade por danos causados ao meio-ambiente, ao consumidor, a bens e direitos de valor artístico, estético, histórico, turístico e paisagístico e dá outras providências, a qual sofreu, nos transcorrer desses anos de sua publicação, inúmeras modificações e inclusões de novos conceitos de infrações que serão consideradas passiveis de investigações. Conforme definiu a referida lei, os legitimados ativos da ação de improbidade administrativa são somente aqueles previstos no artigo 17 da mencionada lei, dentre eles, o Ministério Público e a pessoa jurídica interessada.

Em seu magistério, NEVES ${ }^{1}$ assevera que, prevendo o artigo 17, da LIA, a legitimidade da "pessoa jurídica interessada", questiona-se se todas as pessoas jurídicas previstas no artigo 1으 da mesma lei tem legitimidade para a propositura da ação de improbidade. Acrescenta que:

para parcela da doutrina, a legitimidade restringe-se às pessoas jurídicas de direito público vitimadas pelo ato de improbidade administrativa, abrangendo a Administração Direta (União, Estado e Município), Indireta e Fundacional.

Confessa o professor que possui entendimento ampliativo, no sentido de que todas as pessoas jurídicas que possam ser prejudicadas por ato de improbidade administrativa tenham legitimidade ativa para a propositura da ação ora analisada.

É nessa extensão/abertura/concessão da lei que se pode discutir academicamente a possibilidade do sindicato ser titular de eventual ingresso de ação civil por ato de improbidade administrativa praticado, por exemplo, por um gestor público que as normas estipulados nos artigos 9o, 10 e 11 da LIA (Lei de Improbidade Administrativa), uma vez que, dentre as hipóteses, por ser

\footnotetext{
${ }^{1}$ NEVES, Daniel Amorim Assumpção. Manual de Improbidade Administrativa / Daniel Amorim Assumpção Neves, Rafael Carvalho Rezende de Oliveira. - 3. a ed. rev., atual. e ampl. - Rio de Janeiro: Forense: São Paulo: Editora Método, 2015 (fls. 136-verso).
} 
recebedor contribuição sindical, é sujeito passivo de ato de improbidade administrativa, portanto, segundo entendimento acima, seria legitimado para o ingresso de Ação Civil Pública.

No que tange às posições jurisprudenciais, em detida pesquisa, juntos aos principais tribunais de justiça do país, pôde-se constatar que é pacificado que os sindicatos são aceitos como pessoa legítima para ingresso de ações civis, ficou, contudo, anotado que há restrição em sua atuação, de forma que somente é recebida ações cujo objeto seja a representação dos interesses de seus filiados, cuja matéria tenha pertinência temática com as atribuições anotadas em seu estatuto.

\section{REFERÂNCIAS}

NEVES, Daniel Amorim Assumpção. Manual de Direito Processual Civil. Rio de Janeiro: Forense: São Paulo: Editora Método, 2009, p- 71 - 97.

Manual de Improbidade Administrativa. Daniel Amorim Assumpção Neves,

Rafael Carvalho Rezende de Oliveira. - 3. a ed. rev., atual. e ampl. - Rio de Janeiro: Forense: São Paulo: Editora Método, 2015.

FLEXA, Alexandre. Novo Código de Processo Civil. O que é inédito. O que é novo. O que foi suprimido. 2a Tiragem / Alexandre Flexa, Daniel Macedo, Fabrício Bastos. Salvador: Editora JusPodium, 2015, p. 54 e 55.

MARINONI, Luiz Guilherme. Novo código de processo civil comentado / Luiz Guilherme Marinoni, Sérgio Arenhart, Daniel Mitidiero. - São Paulo: Editora Revista dos Tribunais, 2015.

MORAES, Alexandre de. Direito constitucional. 31. ed. - São Paulo: Atlas, 2015. cap. 9: Administração Pública, Improbidade Administrativa e Ação Civil Pública, p. 385-389.

DIDIER Jr, Fredie. Curso de direito processual: introdução ao direito processual civil, parte geral e processo de conhecimento. 18. ed. Salvador: Editora Jus Podium, 2016.

Curso de direito processual: processo coletivo / Fredie Didier Jr., Hermes

Zaneti Jr. - 10. ed. - Salvador: Editora Jus Podium, 2016.

MORAES, Alexandre de. Direito constitucional. 31. ed. - São Paulo: Atlas, 2015. cap. 9: Administração Pública, Improbidade Administrativa e Ação Civil Pública, p. 385-389.

NUNES JUNIOR, Flávio Martins Alves. Remédios Constitucionais. 5. ed. rev. e atual. - São Paulo: Editora dos Tribunais, 2014. - (Coleção Elementos do Direito; 13 / Coordenação Marco Antônio Jr., Darlan Barroso). 